\title{
Biochemical and physiological characterization of three rice cultivars under different daytime temperature conditions
}

\author{
Alefsi David Sánchez-Reinoso ${ }^{1}$ Gabriel Garcés-Varón², and Hermann Restrepo-Díaz ${ }^{*}$
}

\begin{abstract}
Heat stress due to high daytime temperatures is one of the main limiting factors in rice (Oryza sativa L.) yield in Colombia. Thus, the objective of the present research was to analyze the effect of three different daytime temperatures $(25,35$, and $40{ }^{\circ} \mathrm{C}$ ) on the physiological responses of three Colombian rice cultivars (F60, F733, and F473), thereby contributing to the knowledge of rice acclimation mechanisms. For $10 \mathrm{~d}$, eight plants of each of the three cultivars were subjected daily to $5 \mathrm{~h}$ periods of 35 and $40{ }^{\circ} \mathrm{C}$. The control treatment corresponded to normal growth conditions $\left(25^{\circ} \mathrm{C}\right)$. Thermal stress was assessed based on a series of physiological and biochemical parameters. The $35^{\circ} \mathrm{C}$ treatment produced photosynthetic and respiratory differences in all three cultivars. At $40{ }^{\circ} \mathrm{C}$, ' $\mathrm{F} 60$ ' displayed the lowest photosynthetic rate and the highest respiratory rate. Although this cultivar experienced particularly strong electrolyte leakage and changes in proline when subjected to the high-temperature treatments, similar trends were observed in 'F733' and ' $\mathrm{F} 473$ '. At $40{ }^{\circ} \mathrm{C}$, the concentration of malondialdehyde (MDA) was lower in 'F473' than in the other cultivars. These results may explain the poor agronomic performance of 'F60' in the field under daytime heat stress. The methodologies employed in the present work may be useful in Colombian rice breeding programs, particularly for the selection of heat-tolerant breeding stocks.
\end{abstract}

Key words: Malondialdehyde, Oryza sativa, photosynthesis, proline, respiration, thermal stress.

\section{INTRODUCTION}

Rice (Oryza sativa L.) is a major crop in Colombia, with a production of $2283981 \mathrm{t}$ of grain on a total area of 445414 ha in 2010 (DANE-Fedearroz, 2013). Rice plants are susceptible to unfavorable environmental conditions, such as high temperatures, during specific developmental periods (Fageria, 2007; Jagadish et al., 2007). Among physiological processes, photosynthesis is one of the most susceptible to heat stress, as the photosynthetic rate can decrease by $50 \%$ when temperatures exceed 35 ${ }^{\circ} \mathrm{C}$ (Taniyama et al., 1988; Restrepo-Diaz and GarcesVaron, 2013). Heat stress may also affect leaf chlorophyll content, the ratio of chlorophyll variable fluorescence to maximum fluorescence $\left(\mathrm{F}_{\mathrm{v}} / \mathrm{F}_{\mathrm{m}}\right)$, non-photochemical quenching (NPQ) and/or the activation of RuBisCO in rice (Cao et al., 2009; Yin et al., 2010).

Biochemical changes are another aspect of plant acclimation to heat stress (Wahid et al., 2007). Proline accumulation plays an important role in the metabolism of stressed plants (particularly those under high-temperature

\footnotetext{
${ }^{1}$ Universidad Nacional de Colombia, Departamento de Agronomía, Carrera $30 \mathrm{~N}^{\circ}$ 45-03, 111321 Bogotá, Colombia.

*Corresponding author (hrestrepod@unal.edu.co).

${ }^{2}$ Federación Nacional de Arroceros, Seccional Saldaña, Cra. $18 \mathrm{~N}^{\circ}$ 23-112, 733570 Saldaña, Colombia.

Received: 24 February 2014.

Accepted: 10 July 2014.
}

doi:10.4067/S0718-58392014000400001 conditions), not only as a source of $\mathrm{C}$ or $\mathrm{N}$ but also as a membrane stabilizer (Jouve et al., 1993; Hare and Cress, 1997). Proline levels in rice increase during short periods of exposure to high temperatures and decrease when these conditions are prolonged; thus, proline is an important indicator of stress in this species (Tang et al., 2008). Elevated levels of proline are associated with genotypes that are better adapted to intense environmental demands (Ahmed and Hasan, 2011).

High temperatures may also affect membrane stability through lipid peroxidation, leading to the production of peroxide ions and malondialdehyde (MDA) (Wahid et al., 2007). Therefore, changes in the concentration of MDA may also be a good indicator of membrane structural integrity under temperature stress (Cao et al., 2008). Challenging temperature conditions of $37^{\circ} \mathrm{C} / 30{ }^{\circ} \mathrm{C}$ (day/ night) increase the electrolyte leakage percentage and MDA content in rice (Zhang et al., 2009). Similar results were also obtained by Liu et al. (2013) in rice plants.

Recent decreases in yields of Colombian rice cultivars have been primarily attributed to increases in the maximum and minimum temperatures of up to $3{ }^{\circ} \mathrm{C}$ above historical averages, particularly during dry season or under specific environmental phenomena such as El Niño (Castilla et al., 2010). Colombian rice cultivars such as 'Fedearroz 60' ('F60'), 'Fedearroz 733' ('F733'), and 'Fedearroz 473' ('F473') have become widely cultivated (Restrepo and Garcés, 2013). Castilla et al. (2010) reported that rice grain yield can reduce around $60 \%$ in rice plants of 
'F60' under high daytime temperature (above $35{ }^{\circ} \mathrm{C}$ ). In addition, Restrepo-Diaz and Garces-Varon (2013) showed that the leaf photosynthesis in rice plants 'F733' diminished approximately $30 \%$ at $40{ }^{\circ} \mathrm{C}$. However, biochemical responses of Colombian rice cultivars during acclimation to high-temperature conditions have not been well documented. Therefore, the objective of this study was determine the likely acclimation mechanisms of three Colombian rice cultivars under high-temperature conditions by quantifying the effects of three different day temperatures $\left(25,35\right.$, and $\left.40^{\circ} \mathrm{C}\right)$ on physiological processes such as photosynthesis, transpiration and respiration, as well as biochemical processes such as the production of proline and MDA.

\section{MATERIALS AND METHODS}

\section{Plant materials and growing conditions}

Seeds of 'Fedearroz 60' ('F60'), 'Fedearroz 733' ('F733') and 'Fedearroz 473' ('F473') were sown in $350 \mathrm{~mL}$ plastic pots containing soil as the substrate. The plastic pots were then placed in a sunlit phytotron (MLR-351H, Sanyo, Bensenville, Illinois, USA) at the Laboratory of Plant Physiology at the Universidad Nacional de Colombia, Bogotá campus. The growing conditions inside the phytotron during the experiment were $25^{\circ} \mathrm{C}$ day temperature, $18{ }^{\circ} \mathrm{C}$ night temperature, $70 \%$ average relative humidity, and 12:12 h photoperiod. After $5 \mathrm{~d}$ germination, seedlings were thinned to two plants per pot. The pots were fertirrigated daily with $40 \mathrm{~mL}$ complete fertilizer solution (Wuxal, Bayer CropScience, Bogota DC, Colombia) at a concentration of $4 \mathrm{~mL} \mathrm{~L}^{-1} \mathrm{H}_{2} \mathrm{O}$. The fertilizer composition was: total $\mathrm{N} 160 \mathrm{~g} \mathrm{~L}^{-1}$ (ammonia $\mathrm{N}$, $38 \mathrm{~g} \mathrm{~L}^{-1}$; nitric $\mathrm{N}, 12 \mathrm{~g} \mathrm{~L}^{-1}$; urea $\mathrm{N}, 110 \mathrm{~g} \mathrm{~L}^{-1}$ ); assimilable $\mathrm{P}\left(\mathrm{P}_{2} \mathrm{O}_{5}\right) 160 \mathrm{~g} \mathrm{~L}^{-1}$; soluble $\mathrm{K}\left(\mathrm{K}_{2} \mathrm{O}\right) 120 \mathrm{~g} \mathrm{~L}^{-1} ; 10 \mathrm{~g} \mathrm{~B}$ $\mathrm{L}^{-1} ; 0.21 \mathrm{~g} \mathrm{Cu} \mathrm{L}^{-1 *} ; 0.43 \mathrm{~g} \mathrm{Fe} \mathrm{L}^{-1} ; 0.36 \mathrm{~g} \mathrm{Mn} \mathrm{L}^{-1} ; 0.07 \mathrm{~g}$ Mo L ${ }^{-1} ; 10 \mathrm{~g} \mathrm{Zn} \mathrm{L}^{-1 *}$ (*chelated with EDTA - pH of $10 \%$ solution 6.5; density at $25^{\circ} \mathrm{C} 1.40 \mathrm{~g} \mathrm{~cm}^{-3}$ ).

\section{Heat stress treatments}

Eight plants of each of the three cultivars were subjected to three heat stress treatments at $45 \mathrm{~d}$ after seed emergence (DAE). Plants were exposed to $35^{\circ} \mathrm{C}$ or $40^{\circ} \mathrm{C}$ (heat stress treatments), respectively; for $5 \mathrm{~h}$ (from 11:00 to 16:00 $\mathrm{h}$, to simulate field conditions) over ten consecutive days to achieve long-term high-temperature stress. The experiment ended at $55 \mathrm{DAE}$.

\section{Leaf chlorophyll determination and leaf proline content}

Leaf portions were placed in $80 \%(\mathrm{v} / \mathrm{v})$ acetone, and chlorophyll extraction was completed using the method described by Wintermans and De Mots (1965). At 55 DAE, three $1 \mathrm{~cm}$ veinless leaf blade sections (20 to 30 $\mathrm{mg}$ fresh weight) were taken from a fully developed leaf and homogenized in $8 \mathrm{~mL}$ ethanol solution. The sample was centrifuged at $3000 \mathrm{rpm}$. The absorbance at 663 and $645 \mathrm{~nm}$ were assessed in a spectrophotometer (Spectronic BioMate 3 UV-Vis, Thermo, Madison, Wisconsin, USA). Absorbance data were used to determine leaf chlorophyll concentration.

Leaf proline content was estimated using the technique described by Bates et al. (1973). At 55 DAE, $0.3 \mathrm{~g}$ of fully developed leaf material was homogenized in liquid nitrogen and reacted with $10 \mathrm{~mL}$ of $3 \%$ aqueous solution of sulfosalicylic acid before being filtered through $\mathrm{nr}$ 2 Whatman paper. A $2 \mathrm{~mL}$ aliquot of this filtrate was sampled and reacted with $2 \mathrm{~mL}$ acid ninhydrin and $2 \mathrm{~mL}$ glacial acetic acid. This mixture was placed in a water bath at $90{ }^{\circ} \mathrm{C}$ for $1 \mathrm{~h}$. The reaction was then stopped by incubation on ice. The resulting solution was dissolved in $4 \mathrm{~mL}$ toluene by vigorously shaking the test tubes using a vortexer. The absorbance was measured at $520 \mathrm{~nm}$ in the spectrophotometer. The leaf proline concentration was obtained from a standard curve and calculated on a fresh weight basis as follows: $[(\mu \mathrm{g}$ proline $/ \mathrm{mL} \times \mathrm{mL}$ toluene $\left.) / 115.5 \mu \mathrm{g} \mu \mathrm{mol}^{-1}\right] /[\mathrm{g}$ sample $/ 5]=\mu \mathrm{mol}$ proline $/ \mathrm{g}$ fresh material.

\section{Lipid oxidation estimation}

Lipid oxidation assessment (MDA production) was performed using the thiobarbituric acid (TBA) method described by Hodges et al. (1999). The leaf MDA content was only estimated in rice plants subjected to $40{ }^{\circ} \mathrm{C}$ over ten consecutive days. After this stress period (55 DAE), $0.3 \mathrm{~g}$ fully developed leaf material was homogenized with liquid nitrogen and then reacted with $3 \mathrm{~mL} 0.1 \%$ trichloroacetic acid. The mixture was centrifuged at 3000 $\mathrm{g}$ for $10 \mathrm{~min}$. A $1 \mathrm{~mL}$ aliquot of the resulting supernatant was placed in each of two test tubes containing $4 \mathrm{~mL}$ of $10 \%$ trichloroacetic acid, one of which also contained $0.65 \%$ thiobarbituric acid. Subsequently, test tubes were placed in a water bath at $90{ }^{\circ} \mathrm{C}$ for $25 \mathrm{~min}$. After this period, the reaction was stopped by incubation on ice. Samples were centrifuged again at $3000 \mathrm{~g}$ for $10 \mathrm{~min}$. The absorbances at 440,532, and $600 \mathrm{~nm}$ were then measured in the spectrophotometer. An extinction coefficient was used to obtain the MDA concentration (157 $\mathrm{M} \mathrm{mL}^{-1}$ ).

\section{Net photosynthetic rate}

Carbon assimilation was determined using a portable photosynthesis meter (LI-COR 6200, Lincoln, Nebraska, USA). Between 52 and 55 DAE, measurements were taken from two fully developed leaves while plants were subjected to temperature treatments. During the photosynthesis measurements, the conditions within the cuvette were as follows: Photosynthetic active radiation (PAR) greater than $800 \mu \mathrm{mol} \mathrm{m} \mathrm{m}^{-2} \mathrm{~s}^{-1}$, leaf temperature 27 $\pm 5^{\circ} \mathrm{C}$, and leaf to air water vapor pressure difference 1.8 $\pm 0.5 \mathrm{kPa}$. 


\section{Transpiration plant rate (TPT) and respiration rate}

The TPT was measured using the gravimetric technique described by Blom-Zandstra et al. (1995), which consisted of covering pots with plastic bags to prevent water loss due to evaporation and weighing pots daily before and after irrigation between 52 and 55 DAE. The transpiration rate was expressed in $\mathrm{mg}_{\text {water }} \mathrm{g}^{-1} \mathrm{FW} \mathrm{h}^{-1}$.

To measure respiration, plants were placed in airtight 4 L plastic chambers fitted with infrared $\mathrm{CO}_{2}$ sensors $\left(\mathrm{CO}_{2}-\right.$ BTA, Vernier, Beaverton, Oregon, USA) connected to a portable interface (LabQuest, Vernier, Beaverton, Oregon, USA). Before plants were placed in these chambers, each pot was covered with a plastic bag to prevent soil respiration from confounding the quantification of plant tissue respiration. The chambers were then placed in total darkness for a period of $300 \mathrm{~s}$, during which the sensors estimated the $\mathrm{CO}_{2}$ concentration $\left(\mathrm{mg} \mathrm{kg}^{-1}\right)$ in the chamber every $4 \mathrm{~s}$, resulting in a linear trend curve. The plant respiration rate $\left(\mathrm{mmol} \mathrm{CO} \mathrm{Kg}^{-1} \mathrm{FW} \mathrm{h}^{-1}\right)$ was determined from the slope of the linear regression $\left(\mathrm{mg} \mathrm{kg}^{-1} \mathrm{~s}^{-1}\right)$ and calculated based on the total plant fresh weight. These measurements were obtained simultaneously with those of photosynthesis and transpiration.

\section{Membrane permeability damage resulting from electrolyte leakage}

Plasma membrane damage was evaluated using the percentage of electrolyte leakage protocol described by Jiang and Zhang (2001). After the stress period at 55 DAE, approximately $0.3 \mathrm{~g}$ samples of fresh leaves were cut into $1 \mathrm{~cm}$ pieces and placed into test tubes containing $30 \mathrm{~mL}$ of deionized water. Subsequently, tubes were incubated in a $30{ }^{\circ} \mathrm{C}$ water bath for $2 \mathrm{~h}$, after which the initial electrical conductivity $\left(\mathrm{EC}_{1}\right)$ of the medium was measured. Samples were then placed in a boiling water bath at $95{ }^{\circ} \mathrm{C}$ for 15 min to release all of the electrolytes. After the samples were cooled, their final electrical conductivity $\left(\mathrm{EC}_{2}\right)$ was determined. The electrolyte percentage was calculated using the following formula: $\left[\mathrm{EC}_{1} / \mathrm{EC}_{2}\right] \times 100$.

\section{$F_{\mathrm{v}} / \mathbf{F}_{\mathrm{m}}$ ratio measurements}

A continuous excitation fluorometer (Handy PEA, Hansatech Instruments, Kings Lynn, UK) was used to determine the ratio of chlorophyll variable fluorescence to maximum fluorescence $\left(\mathrm{F}_{\mathrm{v}} / \mathrm{F}_{\mathrm{m}}\right)$. Two fully developed leaves (same used for the photosynthesis determination) were used to assess $F_{m}$ and $F_{v} / F_{m}$ ratio. After the baseline $\left(\mathrm{F}_{0}\right)$ and maximum $\left(\mathrm{F}_{\mathrm{m}}\right)$ fluorescence were determined, these data were used to calculate the variable fluorescence $\left(F_{v}=F_{m}-F_{0}\right)$ and the variable to maximum fluorescence ratio $\left(\mathrm{F}_{\mathrm{v}} / \mathrm{F}_{\mathrm{m}}\right)$. All these parameters were determined at the end of the stress period (55 DAE) by adapting leaves to the dark using lightweight leaf clips for at least $10 \mathrm{~min}$ before obtaining measurements. $F_{v} / F_{m}$ readings were determined with maximum light intensity of up to 3000 $\mu \mathrm{mol} \mathrm{m} \mathrm{m}^{-2} \mathrm{~s}^{-1}$ at the leaf sample surface.

\section{Experimental design and statistical analysis}

The experiment was conducted under a factorial design with eight plants per treatment: the main factor was cultivar (F60, F733, and F473), and the secondary factor was daytime temperature $\left(25,35\right.$, and $\left.40{ }^{\circ} \mathrm{C}\right)$. Before analysis, the percentage values were arcsine transformed. When significant differences were found, means were compared using Tukey's test at a significance value of $\mathrm{P}=$ 0.05 . Data were analyzed using Statistix v 8.0 (Analytical Software, Tallahassee, Florida, USA).

\section{RESULTS}

\section{Net photosynthesis and transpiration rate}

The net photosynthetic and transpiration rates of the three Colombian rice cultivars under different daytime temperatures over $10 \mathrm{~d}$ are presented in Figures $1 \mathrm{~A}$ and 1B; Figure 1A shows the effect of Temperature $\times$ Cultivar interaction on the net photosynthetic rates of the three cultivars. An increase in the leaf photosynthetic rate of each of the three cultivars was observed when the daytime temperature was increased from 25 to $35^{\circ} \mathrm{C}$. Photosynthesis increased by $\sim 44.5 \%, \sim 17.6 \%$ and $\sim 25 \%$ in plants
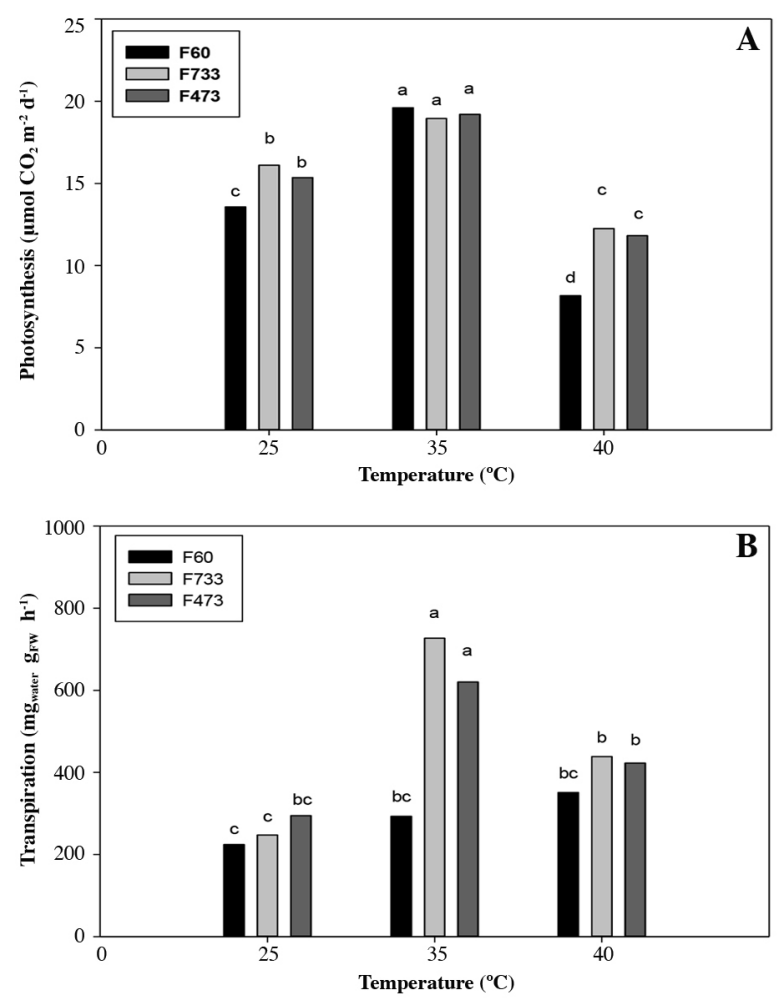

Figure 1. Effect of three different daytime temperatures $(25,35$, and $40{ }^{\circ} \mathrm{C}$ ) on photosynthesis (A) and transpiration (B) of three Colombian rice cultivars (F60, F733, and F473). For $10 \mathrm{~d}$, plantlets were kept in growth chambers and daily exposed to 5-h temperature treatments. Different letters indicate significant differences according to Tukey's means comparison test $(\mathbf{P} \leq 0.05)$. 
of 'F60', 'F733', and 'F473', respectively; over this temperature interval. However, all rice cultivars exhibited significant reductions in photosynthesis at $40{ }^{\circ} \mathrm{C}$. At this temperature, leaf photosynthesis of 'F60' was remarkably reduced by approximately $40 \%$ compared to the other two cultivars, which exhibited reductions of $\sim 23 \%$.

The effects of the Cultivar $\times$ Temperature interaction on total plant transpiration (TPT) are shown in Figure 1B. In general, TPT was enhanced by increased daytime temperatures (from 25 to $35^{\circ} \mathrm{C}$ ), most notably in the rice plants ' $\mathrm{F} 473$ ' and 'F733'. When the daytime temperature was further increased from 35 to $40{ }^{\circ} \mathrm{C}$, the TPT of these cultivars decreased to the same level as in 'F60', which did not exhibit any significant variation in TPT at the three different daytime temperatures.

\section{$F_{\mathrm{v}} / \mathbf{F}_{\mathrm{m}}$ ratio and leaf chlorophyll pigments}

The efficiency of PSII $\left(\mathrm{F}_{\mathrm{v}} / \mathrm{F}_{\mathrm{m}}\right.$ ratio $)$ decreased inversely with temperature (Figure 2). At the control temperature, this ratio was greater than 0.8 , whereas at 35 and $40{ }^{\circ} \mathrm{C}$ the ratio decreased to approximately 0.75 in all of the studied cultivars. Since $F_{v} / F_{m}$ values below 0.8 can be indicating a possible negative effect of abiotic stress on plant functioning (Ritchie, 2006; Gorbe and Calatayud, 2012), therefore our data suggest that prolonged exposure to 35 and $40{ }^{\circ} \mathrm{C}$ may trigger PSII malfunctioning in these rice cultivars. The leaf chlorophyll contents $(a, b$, and total) of the three studied rice cultivars under the daytime temperature treatments are presented in Figure 3. Overall, leaf chlorophyll pigments ( $a, b$, and total) remained unchanged for the studied cultivars; however, of the cultivars studied, concentrations of these pigments were lowest in 'F473'.

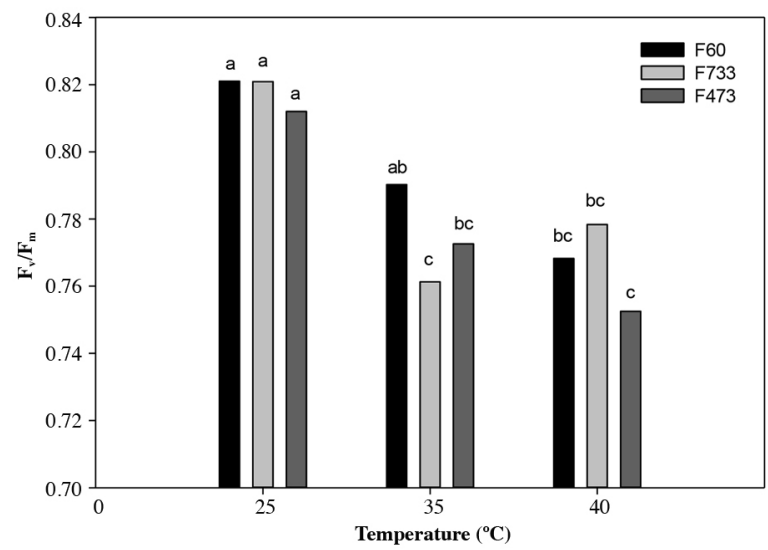

Figure 2. Effect of three different daytime temperatures $(25,35$, and $40{ }^{\circ} \mathrm{C}$ ) on the ratio of chlorophyll variable fluorescence to maximum fluorescence $\left(F_{\mathrm{v}} / \mathrm{F}_{\mathrm{m}}\right)$ in three Colombian rice cultivars $(\mathrm{F} 60, \mathrm{~F} 733$, and F473). For $10 \mathrm{~d}$, plantlets were kept in growth chambers and daily exposed to 5-h temperature treatments. Different letters indicate significant differences according to Tukey's means comparison test $(\mathrm{P} \leq 0.05)$.

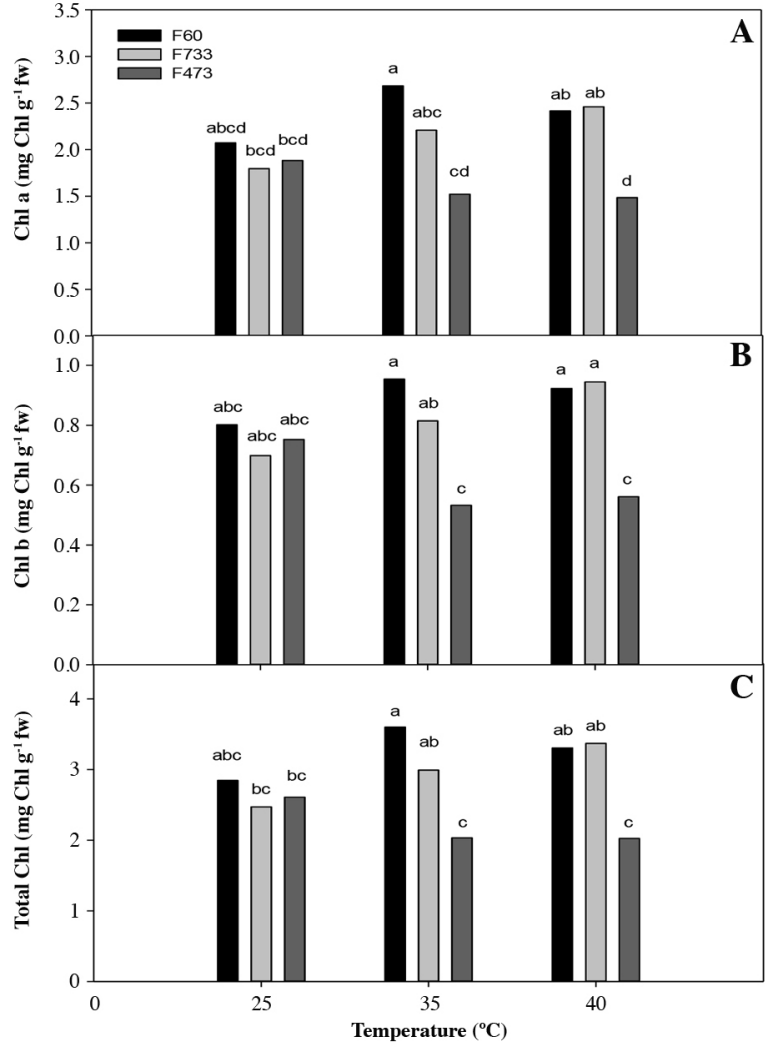

Figure 3. Effect of three different daytime temperatures $(25,35$, and $40^{\circ} \mathrm{C}$ ) on the contents of chlorophyll a (A), chlorophyll b (B) and total chlorophylls $(C)$ of three Colombian rice cultivars (F60, F733, and F473). For 10 d, plantlets were kept in growth chambers and daily exposed to 5-h temperature treatments. Different letters indicate significant differences according to Tukey's means comparison test $(\mathbf{P} \leq \mathbf{0 . 0 5})$.

\section{Respiration rate}

The Cultivar $\times$ Heat stress treatment interaction produced significant changes in the plant respiration rate in the three studied rice cultivars (Figure 4). Under the different temperature treatments, a linear relationship between

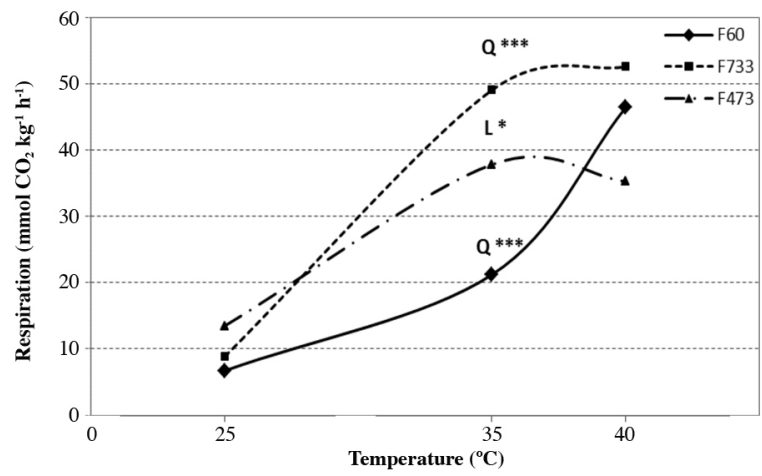

Figure 4. Effect of three different daytime temperatures $(25,35$, and $\left.40{ }^{\circ} \mathrm{C}\right)$ on respiration of three Colombian rice cultivars (F60, F733, and F473). For $10 \mathrm{~d}$, plantlets were kept in growth chambers and daily exposed to 5-h temperature treatments. Different letters indicate significant differences according to Tukey's means comparison test $(\mathbf{P} \leq \mathbf{0 . 0 5})$. 
temperature and respiration rate was observed for ' $\mathrm{F} 60$ ' plants $(\mathrm{P} \leq 0.05)$, and a quadratic relationship was observed for ' $\mathrm{F} 733$ ' and ' $\mathrm{F} 473$ ' plants $(\mathrm{P} \leq 0.001)$. The highest respiratory rate increases were observed in 'F60' and 'F733' when temperature reached $40{ }^{\circ} \mathrm{C}$.

\section{Proline content}

Proline content increased by $\sim 200 \%$ in each of the three cultivars when daytime temperature increased from 25 to $35^{\circ} \mathrm{C}$. However, proline content decreased by $\sim 45 \%$ and $\sim 35 \%$ in 'F733' and 'F473', respectively, as the temperature increased from 35 to $40{ }^{\circ} \mathrm{C}$. By contrast, proline concentration remained unchanged in ' $\mathrm{F} 60$ ' rice plants over this temperature range (Figure 5).

\section{Assessment of membrane stability based on electrolyte leakage and lipid oxidation (MDA content)}

Assessing the effect of the different daytime temperatures on membrane stability based on the percentage of electrolyte leakage revealed that 'F60' and 'F733' seemed to be the most susceptible. These cultivars exhibited respective electrolyte losses of $\sim 20 \%$ and $\sim 15 \%$ at both 35 and $40{ }^{\circ} \mathrm{C}$ (Figure 6). However, 'F473' plants did not exhibit changes in membrane stability throughout the heat stress treatment. The effect of treatments on MDA concentration confirms our previous results. Lipid oxidation (MDA content) was notably higher in the rice plants ' $\mathrm{F} 60$ ' at $40{ }^{\circ} \mathrm{C}$. High temperatures increased the MDA content in 'F60' by 72\% compared to 'F473' and by $\sim 12 \%$ compared to 'F733' (Figure 7).

\section{DISCUSSION}

The TPT increased significantly in 'F733' and 'F473' plants as the temperature increased from 25 to $35^{\circ} \mathrm{C}$, most likely as part of a leaf cooling acclimation mechanism to prevent metabolic damage (Baker and Allen, 1993; Wahid et al.,

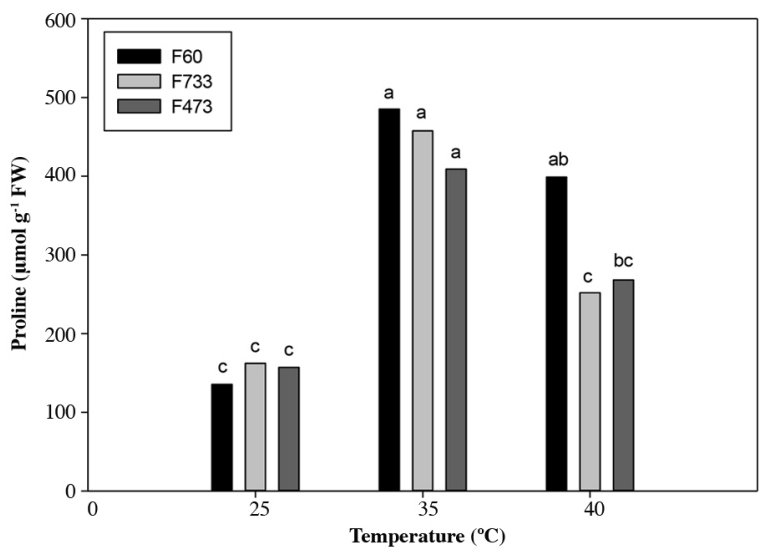

Figure 5. Effect of three different daytime temperatures $(25,35$, and $40{ }^{\circ} \mathrm{C}$ ) on proline content of three Colombian rice cultivars ( $F 60$, F733, and F473). For $10 \mathrm{~d}$, plantlets were kept in growth chambers and daily exposed to 5-h temperature treatments. Different letters indicate significant differences according to Tukey's means comparison test $(\mathrm{P} \leq \mathbf{0 . 0 5})$.

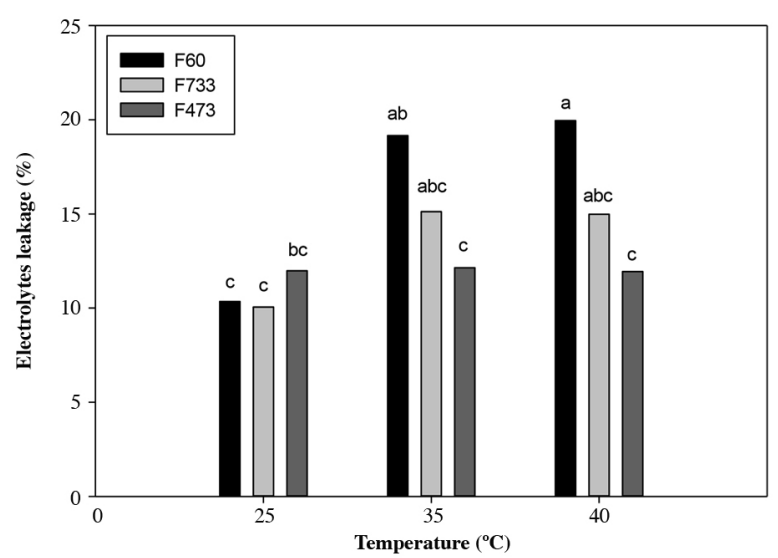

Figure 6. Effect of three different daytime temperatures $(25,35$, and $40{ }^{\circ} \mathrm{C}$ ) on cell membrane electrolyte leakage of three Colombian rice cultivars (F60, F733, and F473). For 10 d, plantlets were kept in growth chambers and daily exposed to 5-h temperature treatments. Different letters indicate significant differences according to Tukey's means comparison test $(\mathrm{P} \leq \mathbf{0 . 0 5})$.

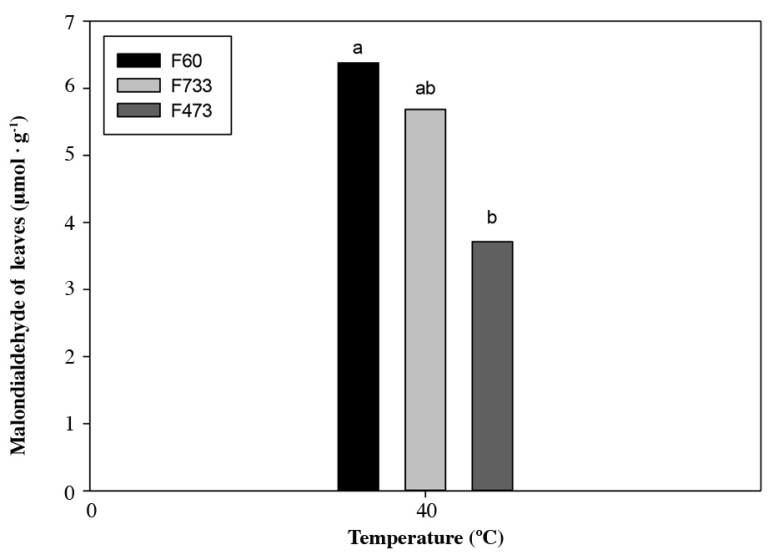

Figure 7. Effect of daytime temperature $\left(40^{\circ} \mathrm{C}\right)$ on malondialdehyde (MDA) content in three Colombian rice cultivars (F60, F733, and F473). For $10 \mathrm{~d}$, plantlets were kept in growth chambers and daily exposed to 5-h temperature treatments. Different letters indicate significant differences according to Tukey's means comparison test $(\mathrm{P} \leq$ 0.05).

2007). However, the decrease in transpiration in these two cultivars at $40{ }^{\circ} \mathrm{C}$ likely represents a strategy to prevent water loss (Stone, 2001). The increase in temperature from 25 to $35^{\circ} \mathrm{C}$ also enhanced photosynthesis in each of the three Colombian rice cultivars. However, photosynthesis was significantly reduced at $40{ }^{\circ} \mathrm{C}$, most notably in plants 'F60' (Figure 1A and B). Studies performed by Taniyama et al. (1988) yielded similar results for Indica rice cultivars; net photosynthetic rates of four rice cultivars improved when temperature increased from 25 to $35^{\circ} \mathrm{C}$ but were negatively affected at $40{ }^{\circ} \mathrm{C}$. Cao et al. (2009) have suggested that high leaf photosynthesis under heat stress conditions might be a good indicator of heat stress tolerance. Our results indicate that 'F60' is susceptible to high temperatures $\left(\geq 35^{\circ} \mathrm{C}\right)$, in agreement with field observations of drastic yield reductions of ' $\mathrm{F} 60$ ' plants under heat stress (Castilla et al., 2010). 
Increases in plant respiration rate were higher when temperature increased from 25 to $40^{\circ} \mathrm{C}$. This effect was particularly evident in 'F60' rice plants (Figure 4). These observations are in agreement with those of Jagadish et al. (2012), who reported that an increased respiration rate is a response of rice plants to high temperatures. Previously, Almeselmani et al. (2012) evaluated two wheat cultivars ('PBW343' and 'C306') under elevated daytime temperatures and concluded that ' $\mathrm{C} 306$ ' plants were more tolerant. One of the acclimation mechanisms of ' $\mathrm{C} 306$ ' is to maintain a high net photosynthetic rate and a low respiration rate under heat stress conditions. We observed similar tolerance mechanisms in 'F473'.

Plant acclimation to heat stress has been frequently assessed based on changes in biochemical markers such as MDA and proline (Jouve et al., 1993). The proline content increased in the three rice cultivars examined in this study as the temperature increased from 25 to $35^{\circ} \mathrm{C}$. Recently, Ahmed and Hasan (2011) also observed stimulation of proline production in wheat plants when daytime temperatures increased from 25 to $35^{\circ} \mathrm{C}$. However, the proline content decreased in ' $\mathrm{F} 473$ ' and ' $\mathrm{F} 733$ ', but not 'F60' at $40^{\circ} \mathrm{C}$. Tang et al. (2008) also observed a reduction of proline content in rice leaves at $40^{\circ} \mathrm{C}$ and concluded that this response may be due to plant sensitivity to prolonged stress periods. Proline can also function as a respiration substrate (Britikov et al., 1965); this function may be responsible for the higher proline content of 'F60' plants at $40{ }^{\circ} \mathrm{C}$. In effect, the rapid metabolism of this amino acid likely provides energy for mitochondrial respiration (Hare and Cress, 1997). The MDA content is an important tool for defining the degree of lipid peroxidation, as a higher content of this compound indicates more severe damage of the cell membrane (Heath and Packer, 1968). The MDA concentration was higher in ' $\mathrm{F} 60$ ' plants at $40^{\circ} \mathrm{C}$, as was the percentage of electrolyte leakage, indicating greater cell membrane damage. Similar results were observed in rice plants by Zhang et al. (2009) and Liu et al. (2013), who also reported that the highest values of MDA occurred in the leaves of rice cultivars with enhanced susceptibility to heat stress.

\section{CONCLUSION}

When subjected to heat stress, the rice 'F60' exhibited a significant decrease in the photosynthetic rate coupled to a higher respiration rate and proline accumulation, as well as greater membrane stability damage (elevated concentrations of malondialdehyde and large electrolyte losses). In general, high daytime temperatures $\left(40{ }^{\circ} \mathrm{C}\right)$ caused a reduction around $40 \%, 24 \%, 23 \%$ on the leaf photosynthesis in 'F60', 'F473' and 'F733', respectively. In addition, 'F473' showed a lower malondialdehyde concentration and plant respiration ration. These results can provide an explanation of agronomic performance of 'F60' (susceptible) and 'F473' (tolerant) under heat stress conditions. In consequence, the use of the techniques applied in the present study may provide support to rice breeding programs aiming to select heat stress-tolerant cultivars for Colombian agriculture.

\section{LITERATURE CITED}

Ahmed, J., and M. Hasan. 2011. Evaluation of seedling proline content of wheat genotypes in relation to heat tolerance. Bangladesh Journal of Botany 40:17-22.

Almeselmani, M., P. Deshmukh, and V. Chinnusam. 2012. Effects of prolonged high temperature stress on respiration, photosynthesis and gene expression in wheat (Triticum aestivum L.) varieties differing in their thermotolerance. Plant Stress 6:25-32.

Baker, J.T., and L.H. Allen Jr. 1993. Contrasting crop species responses to $\mathrm{CO}_{2}$ and temperature: rice, soybean and citrus Vegetatio 104:239-260.

Bates, L.S., R.P. Waldren, and I.D. Teare. 1973. Rapid determination of free proline for water-stress studies. Plant and Soil 39:205-207.

Blom-Zandstra, M., C.S. Pot, F.M. Maas, and A.H.C.M. Schapendonk. 1995. Effects of different light treatments on the nocturnal transpiration and dynamics of stomatal closure of two rose cultivars. Scientia Horticulturae 61:251-262.

Britikov, E.A., S.V. Vladimirtseva, and N.A. Musatova. 1965. Transformation of proline in germinating pollen. Fiziologiya Rastenii (English translation) 12:953-967.

Cao, Y-Y., H. Duan, L-N. Yang, Z-Q. Wang, L-J. Liu, and J-C. Yang. 2009. Effect of high temperature during heading and early filling on grain yield and physiological characteristics in Indica rice. Acta Agronomica Sinica 35:512-521.

Cao, Y-Y., H. Duan, L-N. Yang, Z-Q. Wang, S-C. Zhou, and J-C. Yang. 2008. Effect of heat stress during meiosis on grain yield of rice cultivars differing in heat tolerance and its physiological mechanism. Acta Agronomica Sinica 34:2134-2142.

Castilla, L.A., J. Sierra, D. Pineda, J. Echeverry, G. Garcés, R. Perafán, et al. 2010. Arroz y el cambio climático en Colombia: Análisis en la producción arrocera en el Tolima, Periodo 2009 B-2010 A. Revista Arroz 58:4-11.

DANE-Fedearroz. 2013. Encuesta nacional de arroz mecanizado. II semestre de 2012. Departamento Nacional de Estadísticas de Colombia (DANE) y Federación Nacional de Arroceros de Colombia (Fedearroz), Bogotá, Colombia. Available at https:// www.dane.gov.co/files/investigaciones/boletines/arroz/bol_ arroz_IIsem12.pdf (accessed November 2013).

Fageria, N.K. 2007. Yield physiology of rice. Journal of Plant Nutrition 30:843-879.

Gorbe, E., and A. Calatayud. 2012. Applications of chlorophyll fluorescence imaging technique in horticultural research: a review. Scientia Horticulturae 138:24-35.

Hare, P.D., and W.A. Cress. 1997. Metabolic implications of stressinduced proline accumulation in plants. Plant Growth Regulation 21:79-102.

Heath, R.L., and L. Packer. 1968. Photoperoxidation in isolated chloroplasts: I. Kinetics and stoichiometry of fatty acid peroxidation. Archives of Biochemistry and Biophysics 25:189198.

Hodges, D.M., J.M. DeLong, C.F. Forney, and R.K. Prange. 1999. Improving the thiobarbituric acid-reactive-substances assay for estimating lipid peroxidation in plant tissues containing anthocyanin and other interfering compounds. Planta 207:604611 .

Jagadish, S., P. Craufurd, and T. Wheeler. 2007. High temperature stress and spikelet fertility in rice (Oryza sativa L.) Journal of Experimental Botany 58:1627-1635.

Jagadish, S.V.K., E.M. Septiningsih, A. Kohli, M.J. Thomson, C. Ye, E. Redoña, et al. 2012. Genetic advances in adapting rice to a rapidly changing climate. Journal of Agronomy and Crop Science 198:360-373 
Jiang, M., and J. Zhang. 2001. Effect of abscisic acid on active oxygen species, antioxidative defense system and oxidative damage in leaves of maize seedlings. Plant and Cell Physiology 42:1265-1273.

Jouve, L.,F. Engelmann, M. Noirot, and A. Charrier. 1993. Evaluation of biochemical markers (sugar, proline, malondialdehyde and ethylene) for cold sensitivity in microcuttings of two coffee species. Plant Science 91:109-116.

Liu, Q.H., X. Wu, T. Li, J.Q. Ma, and X.B. Zhou. 2013. Effects of elevated air temperature on physiological characteristics of flag leaves and grain yield in rice. Chilean Journal of Agricultural Research 73:85-89.

Restrepo-Diaz, H., and G. Garces-Varon. 2013. Response of rice plants to heat stress during initiation of panicle primordia or grainfilling phases. Journal of Stress Physiology and Biochemistry 9:318-325.

Restrepo, H., and G. Garcés. 2013. Evaluation of low light intensity at three phenological stages in the agronomic and physiological responses of two rice (Oryza sativa L.) cultivars. Agronomía Colombiana 31(2):195-200.

Ritchie, G.A. 2006. Chlorophyll fluorescence: What is it and what do the numbers mean? p. 34-42. In Riley, L.E., R.K. Dumroese, and T.D. Landis (eds.) National Proceedings: Forest and Conservation Nursery Associations 2005. USDA, Forest Service, Rocky Mountain Research Station, Fort Collins, Colorado, USA.
Stone, P. 2001. The effects of heat stress on cereal yield and quality. p. 243-291. In Basra, A.S. (ed.) Crop responses and adaptation to temperature stress. Food Products Press, Binghamton, New York, USA.

Tang, R.S., J.C. Zheng, Z.Q. Jin, D.D. Zhang, Y.H. Huang, and L.G. Chen. 2008. Possible correlation between high temperatureinduced floret sterility and endogenous levels of IAA, GAs and ABA in rice (Oryza sativa L.) Plant Growth Regulation 54:37-43.

Taniyama, T., S.V. Subbaiah, M.L. N. Rao, and K. Ikeda. 1988. Cultivation and ecophysiology of rice plants in the tropics: III. Photosynthesis of rice cultivars of India, measured by the Tsuno's simple method. Japanese Journal Crop Science 57:184-190.

Wahid, A., S. Gelani, M. Ashraf, and M. Foolad. 2007. Heat tolerance in plants: an overview. Environmental and Experimental Botany 61:199-223

Wintermans, J.F.G.M., and A. De Mots. 1965. Spectrophotometric characteristics of chlorophylls $a$ and $b$ and their phenophytins in ethanol. Biochimica et Biophysica Acta 109:448-453.

Yin, Y., S. Li, W. Liao, Q. Lu, X. Wen, and C. Lu. 2010. Photosystem II photochemistry, photoinhibition, and the xanthophyll cycle in heat-stressed rice leaves. Journal of Plant Physiology 167:959966.

Zhang, G.L., L.Y. Chen, S.T. Zhang, H. Zheng, and G.H. Liu. 2009. Effects of high temperature stress on microscopic and ultrastructural characteristics of mesophyll cells in flag leaves of rice. Rice Science. 